\title{
LA HOJA DE AIRE COMO LA BÚSQUEDA IMPOSIBLE
}

\author{
Óscar Gerardo Alvarado Vega
}

\begin{abstract}
RESUMEN
El texto de Joaquín Gutiérrez, La hoja de aire, plantea, a partir del regreso de un costarricense a su patria, la búsqueda de la mujer amada y el fracaso que esta búsqueda implica. Alfonso no logra cuajar la búsqueda de Teresa, aunque la locura que lo gobierna le permite continuar el imposible hallazgo. El desencuentro que se manifiesta con cada uno de los que cruzan su camino no es más que el prólogo de lo que ha de significar su regreso a Costa Rica. La literatura plantea, en esta corta novela, lo que ha de ser la no renuncia a un sueño imposible: el encuentro con el pasado y la negación de un presente que lo despoja, pero al cual enfrenta refugiado en la esperanza. El texto es, por lo tanto, el desarrollo de esa esperanza que comporta Alfonso.
\end{abstract}

Palabras clave: Literatura costarricense, Joaquín Gutiérrez, La hoja de aire.

\begin{abstract}
The text of Joaquín Gutiérrez, La hoja de aire, sets forth from the point of return of a Costa Rican to his country, the search for his true love, and the disaster that is the result of this search. Alfonso is not successful in his search for Teresa, though the insanity that rules him allows him to continue his impossible search. The disregard that is manifested with those who cross his path, is not more than the beginning of what his return to Costa Rica has signified. The author expounds in this short novel what has to be not the renunciation of an impossible dream: the recapturing of his past and the renunciation of a present that is spoiled for him but in which he confronts refuge in hope. The text is at most the development of this hope that Alfonso carries with him.
\end{abstract}

Key words: Costa Rican Literature, Joaquín Gutiérrez, La hoja de aire.

En la narrativa costarricense de la segunda mitad del siglo XX, surge con fuerza el nombre de Joaquín Gutiérrez. Una serie de novelas de este autor responde a su posición ideológica. Este gran escritor, y maestro ajedrecista, a cuya autoría responden Puerto Limón, Murámonos Federico, Te acordás hermano, Te conozco, Mascarita, Cocorí y otras, ocupa un espacio dentro de una textualidad que emerge con gran fuerza en el acontecer literario costarricense como tal. El eterno viajero se posesiona de un lugar en el panorama de la narrativa de nuestro país, a partir de la cual se consagra como uno de los grandes exponentes de nuestra producción cuentística y novelística.

M.L. Óscar Gerardo Alvarado Vega. Licenciado en Filología Española; Magister en Literatura Latinoamericana. Profesor de la Escuela de Estudios Generales, Universidad de Costa Rica. Productor Académico y encargado de la cátedra de Lengua y Literatura de la Universidad Estatal a Distancia. 
En relación con el texto que nos plantea este artículo, fue escrito en el año 1968 y consiste en una narración corta, con un personaje clave que presenta su historia a un escucha que corresponde al propio Joaquín Gutiérrez. El texto, por lo tanto, se desdobla entre ficción y realidad, dando paso a la interiorización del personaje y a la presencia del carácter psicológico de este, que ya ha trabajado Gutiérrez en Puerto Limón, por ejemplo, y de la cual es uno de los impulsores en la narrativa costarricense. Esta nueva dimensión de la elaboración textual se convierte, junto con la obra de Yolanda Oreamuno, La ruta de su evasión, en un nuevo orden desde el cual el personaje adquiere una nueva visión de su entorno, desde la que el lector reconoce los conflictos internos que permean al personaje, y de los cuales este mismo es incapaz de dar cuenta plena.

El texto propiamente está cruzado por la desesperanza y la nostalgia, por la derrota, pero también por la búsqueda permanente del pasado, que se convierte en la búsqueda fracasada de una realidad ya desposeída para el personaje.

Los personajes, pocos, dicho sea de paso, van tejiendo la historia alrededor de un eje básico: Alfonso es el centro de la historia y el narrador de una diégesis que pretende exorcisar a partir de la liberación del lenguaje como expresión de un saber que lo hace ser incomprendido por los otros, pues el texto lo esboza como el único que va en pos de una búsqueda de la que los demás carecen, ya que se adecuan a un presente en el cual se hacen y deshacen con el pasar de los días. Los otros están enseñoreados en el conformismo del dejar pasar, mientras que el "buscador" en realidad se mueve en un perenne ir y venir en pos de un objetivo que no logra culminar y que incluso ya lo ha hecho huir una primera vez.

La crítica manifiesta al vacío cultural en el cual se debate nuestro país se torna en una especie de leit motiv que gobierna el texto desde su inicio. La derrota parece ser no solo la del personaje sino la de una nación que se debate en la hipocresía, la mentira, la incultura, la ignorancia y el vacío de metas. Alfonso escapa a ese entorno, lo cual lo margina y hace que la sociedad se vuelva hostil hacia él. Su búsqueda interior no debe ser solo la propia, sino la de una nación sumida en el pasado, casi similar al que encuentra después de muchos años.

La somnolencia se abate sobre Costa Rica. Las pesadillas que gobiernan a Alfonso corresponden, de alguna manera, al vacío que se agiganta al volver a su patria. De allí que, tal como él mismo lo señala, su enfermedad radica en pensar y en recordar. Su dolor se mueve en el plano de lo psicológico más que en el físico. Ese vacío que lo posee, sin embargo, lo lleva dentro en la medida en que es un incomprendido, pues como actor fracasa en Méjico, no por falta de talento, sino por el rechazo de que es objeto debido a su nacionalidad. El dolor mayor es volver a la patria y no ser aceptado por los suyos. La hoja de aire que es él, se torna más y más persistente, aun contra lo que espera en su país. Esta metáfora de su existencia y su constante deslizarse de un lugar a otro se convierte en el pre-texto de la diferencia en la cual se construye. Alfonso es diferente, pues en su búsqueda inencontrada no halla más que la negación de los demás y ello lo aísla, por lo cual reconfirma su condición de hoja, que se mueve al vaivén de una especie de destino, en procura de una construcción vital que se le vuelve inasible, aun más en un medio que se torna en exceso conformista para su inquieto espíritu.

La ironía, por su parte, es su principal característica; a ella recurre con el objeto de descalificar o de aminorar a los otros y también su pena. El "diálogo" que sostiene con su compañero Joaquín, y que recuerda a Borges hablando con el propio Borges, es la forma que asume para criticar y poner en boca de la ficción el permanente espíritu acrítico del costarricense. Su rodar continuo le da la experiencia y el saber necesarios para afrontar y expresar la crítica que 
asoma a cada paso. La locura que lo gobierna no es más que la desazón y la defensa que asume ante un mundo descarnado que lo acosa y lo margina.

Su lucha, desigual por lo demás, es el preámbulo de la derrota suavizada por un final de locura, ante una búsqueda imposible y simbólica. Tal locura no es más que un descentramiento en medio de la "cordura" social contra la cual se debate y que lo lleva a vagar sin rumbo fijo. Ser loco es para él el signo de una disconformidad ante la cual los otros son incapaces de asimilarse. De tal manera, la hoja de aire no es otra cosa que el paso inexorable de una cordura que los demás no comprenden, pero que los enajena sin darles conciencia de esta. El loco deviene cuerdo y los cuerdos son en verdad los locos en tanto obedecen la imposición de un sistema que los uniforma. Alfonso es loco pues se niega a la clasificación, a la asimilación de lo establecido social y estructuralmente, y tal cuestionamiento lo realiza desde la más profunda interioridad, por lo cual deviene la novela en lectura de la interiorización del personaje. La búsqueda de Teresa, que ya ha partido, es el intento por regresar a un pasado ya ido y el cual es imposible reencontrar.

Su ironía a la hora de definir el mundo que lo rodea, más que protegerlo contra una ciudad que puede considerar hostil, tiende a desenmascararlo, pues descubre a un tipo frágil que se niega a renunciar completamente al pasado y que no acepta, a manera de defensa, la muerte de su ex novia. Todo ello lo reafirma como la hoja de aire que, errabunda, va de un lugar a otro, sin rumbo fijo, casi sujeto a los avatares del destino. Él mismo es consciente de su posición como tal y se reafirma como esa hoja. Paradójicamente, su función de actor y de viajante lo impelen a prescindir de la máscara, es decir, de la careta con la cual se cubre y recubre la sociedad. Tal prescindencia lo termina marginando y lo convierte en otro, que en el fondo no es más que la amenaza para una sociedad de mentira y de ocultamientos. La locura que parece poseerlo no es sino la forma de alienarlo y de restarle la peligrosidad en un medio en que es amenazado, pero que lo percibe como amenazante.

De tal manera, es el actor que no actúa ante una sociedad que se desplaza en la dimensión de lo real, pero que actúa la normalidad e insiste en creerla como tal. El paralelismo entre locura y cordura termina entonces siendo cuestionado con el desarrollo mismo de la novela y reubica a los sujetos ante los ojos del lector, el cual debe construir y reconstruir lo oculto a partir de lo que lee. La interpretación se convierte en funcionamiento vital para el texto, en la medida en que des-cubre a los personajes como son.

La nostalgia que le invade al pensar en el amor que alguna vez dejó se convierte en un motivo más para regresar, aunque solo se encuentra más vacío y derrotado. El desengaño es el gran reencuentro con su nación. Nada ha cambiado para bien, sino que, por el contrario, quizás han empeorado las cosas. La gran ironía de ello es encontrarse con Pedo de culebra, un antiguo amigo, vil, que paradójicamente es abogado y, por lo tanto, es quien vela por la justicia, cuando en realidad su nombre indica todo lo contrario. Está asociado con lo negativo y con lo deleznable. Su mismo encuentro con la hermana le demuestra un imposible: están en dos universos diferentes; ya el encuentro se torna un desencuentro inevitable. La condición que cada uno ostenta socialmente los hace muy diferentes. El fracaso, del cual ya no puede escapar, es el signo evidente de la opresión de un mundo al cual no puede oponerse. Es un universo cambiante que, lejos de permitirle y de pemitirse una incorporación, lo desliga y lo margina, a lo cual él mismo contribuye. Sigue, por lo tanto, reforzando su posición de hoja de aire y se acepta poseído por la diferencia y por la indiferencia con la que los demás lo ven y lo perciben, lo leen y lo interpretan. Por sí mismo es ya un texto que se torna incómodo para los otros, pues 
les cuestiona la mismidad en la cual se desarrollan día tras día. Por ello, la novela construye estos dos polos de percepción del entorno sin que exista una verdadera igualdad de lucha, pues el plano de lo "social" y de la "normalidad" ahoga al personaje y lo evidencia para contrarrestarlo. No es casual que la lucha desigual que sostiene permanentemente contra lo establecido lo lleve poco a poco a la desposesión que intenta imponerle la sociedad.

El fracaso amoroso va acompañado del fracaso en el plano profesional; ambos lo obligan a volver al pasado para reafirmar, contra su voluntad, que la derrota sigue estando allí donde no la esperaba. El pasado es el regreso doloroso contra el cual no puede luchar si no es a partir de la locura que empieza a poseerlo. No debe olvidarse que en algún momento de su vida ya había estado internado en un psiquiátrico, lo cual confirma los problemas por los cuales atraviesa. Unido a ello, la incapacidad para afrontar aquello que escapa de su control, como la muerte de Teresa, lo obliga a desechar la idea de lo real para forjar un sueño, en el que disfraza y enmascara lo inaceptable.

Así, la máscara es la defensa de su imaginación ante la realidad. Ello, por lo tanto, origina un desplazamiento realidad/ fantasía, equivalente a real/engaño. Como actor que es, enmascara la realidad, es decir, no renuncia a la actuación como una forma de defensa ante la opresión del entorno cuando la situación lo requiere, pues se enmascara y desenmascara según algunas situaciones particulares. De este modo, Alfonso no es solo actor en el escenario, sino que lo es fuera de él, a pesar de lo que hemos señalado anteriormente, pues no actúa para parecer otro sino para consolidarse como sí mismo, pero actúa para poder de alguna manera moverse en plano del otro, que le asigna la otredad a él, obviando de esta manera que el otro es siempre quien no soy yo y, por lo tanto, me resulta desconocido, oscuro y, por ende, siniestro. Es la práctica de la locura, solo que la locura de la actuación llevada al plano más legitimador que se pueda concebir. ¿No es acaso la locura una actuación a la que los demás no desean acceder y por eso la repulsan? Es un escape ante la imposibilidad de otro tipo de salida, pero una locura que, escogida o no, margina y desvalora, pues despoja de la palabra que, en definitiva, es símbolo de poder. Su lenguaje, con gran arraigo en su expresión de la interioridad, y que escapa a los demás, lo conforma como cuerdo, pero lo despoja ante la sociedad, desconocedora de su cuestionamiento ante las estructuras dadas.

Por otra parte, su primer escape de Teresa se ve desplazado por el regreso, que no es más que la excusa para el reencuentro con esta. Así, el amor como locura, en tanto se puede volver loco de amor, es la marca plena de lo que ha de ser el resto de su existencia: una práctica de amor continua en un mundo de desamor. La imposibilidad de renuncia ante este, a pesar de la separación, es lo que le permite sostener la locura como forma de amor: Teresa vive y va a su encuentro, pese a la opinión de los demás. Alfonso es loco porque es capaz de percibir lo que los demás no, y por ello escoge el camino de la diferencia, pero como marca de un discurso que, por su forma de adaptarse y de comportarse ante lo que representa el discurso espacio-temporal en que se mueve, lo lleva a buscar lo que es imposible de encontrar. Así, la búsqueda se constituye en la imposibilidad del hallazgo. Buscar es fracaso, pero intento, y Alfonso es un buscador que va en pos de una nostalgia ante la cual se han de cerrar las puertas. Buscar es, entonces, el lugar de lo imposible, pero también el espacio de la necesidad para afrontar el peso devastador de lo cotidiano.

La hoja de aire que alguna vez Teresa le obsequió a Alfonso contribuye a estructurarle una idea de sí mismo. Él es la hoja de aire que enfrenta este peso de lo que ocurre día tras día en una sociedad atrasada e ignorante; es la Costa Rica que encuentra, desposeída de los 
sueños que a él lo han poseído; es la hoja que vaga sin saber a ciencia cierta dónde ha de caer, pero que, en definitiva, ya ha sido expulsada y debe intentar el arraigo en otro espacio, sin saber plenamente cuál.

El inicio mismo del relato tiende a identificarlo con esta hoja, y esa ubicación espacio-existencial que le refiere a su amigo nos va definiendo quién es Alfonso y su carácter nómada, si se quiere, en relación con los demás. El fracaso total no es aceptado por este; de ahí que recurra a la imaginación y se autoconvenza de que Teresa vive. Ello le confiere un acercamiento a una especie de final feliz a la historia y, más que cerrarla, la abre, pues introduce la expectativa ante lo que ha de ser el "encuentro" de los amantes. La ausencia física de Teresa confiere un carácter muy particular al texto, que no tendría si ella apareciera y hablara. Esa aura de misterio que reviste su presencia por medio de las palabras de Alfonso es un elemento más en la imaginación de este, que le confiere características muy definidas a partir de la forma en que la percibe: Teresa está presente como un desdoble de la percepción de su amado; es una mujer ideal ante los ojos de quien la ama y a la cual desea recordar tal como la conoció; de allí el deseo de ir a encontrarla a Cartago y recorrer el mismo potrero en el que esta le regaló la hoja. Es un regreso al pasado y a la nostalgia, en busca de un sueño que le permita seguir aferrado a un ideal, que se escapa pero ante el cual se intenta un apego desesperado, con el fin de no desarraigarse del último de los sueños que aún lo alimenta. Es el intento de la hoja de aire por hallar un asidero en el cual constituirse y brotar de nuevo.

No obstante, tal intención se constituye en el postrer fracaso que lo ha constituido, pues como actor ha sobresalido, pero como persona ha llegado al clímax del fracaso: desposeído de sus padres, de su propia hermana, ante la cual ha dejado de ser lo que era, desposesionado de su patria, de su sueño de reencuentro con Teresa, y con un porvenir ante el cual tiene más barreras que posibilidades de emergencia, en medio de un caos o de un ordenamiento que no es su orden, y por lo cual se halla camino hacia una muerte (física o espiritual) que parece tenerlo signado. Su fracaso es el símbolo de la diferencia que lo caracteriza en relación con los demás y que lo margina de estos.

Lo anterior permite, por lo tanto, señalar que en este relato uno de los temas fundamentales, a la par del fracaso, es el de la frustración que acompaña al personaje. La huida de Alfonso hacia Méjico, con el fin de escapar de la mujer amada, se convierte también en la necesidad de regreso para reconciliarse con esta, a pesar del imposible que ello comporta. El relato, de alguna manera, se vuelve cíclico en la medida en que retoma nuevamente el fracaso, dando lugar al desencuentro que lo lleva a huir en principio, a pesar de que se niegue a aceptarlo al final. El amor imposible es, por lo tanto, otro de los temas, pues fracasa con Teresa y también con Infantina, nombre simbólico, según se percibe por la forma de actuar y pensar del personaje correspondiente. El texto no deja de ser, desde esta perspectiva, también una historia de desamor, de imposibilidad de amor ante el reto que comporta para él su separación y automarginación de lo establecido para definirse a sí mismo su propio rumbo. Ser Alfonso es devenir desde lo alienado, desde lo marginal, desde lo otro... desde la desposesión misma.

De acuerdo con esto, Alfonso, en tanto personaje, se niega a aceptar que es, ante todo, un fracasado, físico y mental, aunque se refugia en la locura para encontrar un sentido a la existencia o a la soledad. Su acción ante la empleada de su hermana, más que un problema de exhibicionismo, es una muestra de locura, incipiente o no, que se va fraguando lentamente, pero que también le permite enfrentar al entorno. Es la producción de un discurso protector que ha de servir como escudo contra el mundo. La locura, de alguna forma, es eso. De allí que 
su descentramiento le permita efectuar tales actos como una forma de actuar ante los demás y de erigirse ante estos. Alfonso es desde su diferencia.

Los desencuentros citados se reafirman en cada uno de los encuentros que Alfonso tiene: fracasa con Teresa, no logra triunfar plenamente como actor en Méjico, es abandonado por Infantina, choca ideológicamente con "Pedo de culebra", asusta a la empleada de su hermana, es echado "sutilmente" por esta última, se desencuentra con una Teresa Gómez que no es la novia de su juventud, no logra hallar a su amada, ignora lo que su amigo Quincho le confiesa y huye hacia un pasado que ya no existe, incapaz de enfrentar el presente que se torna amenazador. El discurso final de Alfonso a su amigo enlaza, curiosamente, su escape con lo que ha sido su acontecer: el engaño, en tanto es actor y enmascara la realidad a su manera más conveniente para conferirle un lugar diferente. Es decir, crea su propio universo con el fin de hacer escapar a los demás, pero también para protegerse a sí mismo. Así, la locura en la cual se ha refugiado, finalmente, le permite asumir la máscara como lo real. Ya sabemos que él mismo ha aceptado su enfermedad o, al menos, que está enfermo:

\footnotetext{
Me internaron un tiempo y de allí salí bien. Yo creo que en el fondo me curé del puro susto, porque hubieras visto el zoológico que había allí dentro. Pero bueno, era una enfermedad como cualquiera otra y no había porqué alarmarse, ¿no es cierto? Unos se enferman de los pulmones, otros de la próstata. Yo me enfermé de eso: de pensar, de recordar (Gutiérrez 1985: 29-30).
}

Llama la atención el hecho de que Alfonso se enferme de recordar y pensar. La cura, por lo tanto, podría ser el olvido y la negación al pensamiento; en su espíritu crítico e inquieto, el pensar es parte esencial de su vitalidad. La crítica implícita se da a la tranquilidad que produce la falta de criticidad y el olvido de la mediocridad en un país que apenas si posee un espíritu medianamente crítico, según se desprende de sus comentarios iniciales al irse a Méjico. La enfermedad que produce el sentimiento es diferente de la enfermedad física, más fácil de curar. La locura está siempre a la vuelta del camino, pues todo a su alrededor es excusa propicia para que esta se desarrolle. Así, la locura es provocada por lo inteligible y lo rechazable. Esta tiene doble vía: lo inaceptable de las normas sociales y el rechazo social de las normas de Alfonso. Al final, no está claro cuál rechazo es mayor, pues el texto, más que cerrarse, se abre al sentido, debido a que la búsqueda de aquel se inicia, y su locura le abre el sentido al final y consolida el del texto, dejando al lector con la duda que no se le aclara. ¿Acaso el texto no emancipa la locura como un camino viable, por no decir que es el mejor camino, al menos para Alfonso? Ello confirma a este personaje, según sus propias palabras, no como "un héroe positivo" sino acaso como un antihéroe, pues está loco para los demás, cuando su heroísmo es más bien la capacidad de nadar contra corriente y rechazar "la razón “ de los demás.

Es así como produce su propio discurso, con el fin de escapar de lo establecido. Su pensar y actuar, de acuerdo con las normas que se ha establecido para sí y que lo condenan socialmente pues lo llevan al sanatorio, donde han de tratarlo de su diferencia para volverlo al mundo de la normalidad, le permiten darse cuenta de que su enfermedad no es debida a la falta de cuestionamiento en torno a lo que sucede sino más bien a su capacidad para expresar su diferencia a partir del rechazo a lo establecido. El recuerdo y su dolorosa génesis cada vez que se recurre a este, lo van ensimismando, apoyado por el continuo pensar desde un punto de vista un poco al modo del solitario y de todas la implicaciones que una soledad de estas comporta. Se guarda su fracaso y lo asume para sí, por lo cual termina de encerrarse en una especie de derrota que lo lleva, inevitablemente, al punto culminante de su declive, el cual ha estado 
en juego a lo largo de todo el texto. Regresa a Costa Rica para decaer paulatinamente y caminar rumbo a la pérdida total, al diluirse en medio de la animadversión social.

Por otra parte, no cabe duda de que la locura de Alfonso y la diferencia con los demás provienen también de su carácter sentimental, romántico y soñador, en medio de una sociedad desprovista de tales valores. El tiempo le cobra y lo despoja, aunque él se aferre a sus ideales y sea incapaz de renunciar a tal sentimentalismo. Allí está también otra de las claves de su derrota: la defensa de sus valores, a contrapelo de lo que los demás crean, se convierte en la gran generadora de sus características. Como todo romántico, la mujer ideal se torna inalcanzable y la soledad e incomprensión son los grandes obstáculos que debe enfrentar y ante los que sucumbe.

La lucha por emerger de las sombras en las cuales se halla se define por su regreso a Costa Rica, en donde no encuentra una salida, sino que más bien camina hacia la desposesión ya señalada y que constituye su regreso al "cementerio" en que ha de sumirse de una vez por todas, después de intentar una vana redención que no llega a culminar. Regresar a la Patria es preparar el camino para la muerte que le espera y de la cual no logra evadirse.

Ante ello, ya hemos apuntado cómo el núcleo familiar carece de validez, en tanto que Alfonso ni siquiera conocía la desaparición de sus padres, de los cuales se desconecta en su viaje a Méjico, durante largos veinte años. Su regreso para encontrarse con la mujer amada y con su hermana es la consolidación de lo disgregado: ya no hay posibilidad de volver atrás y rehacer su vida, la cual parece no tener salida. El encuentro que este tiene con cada uno de los demás personajes es más una filtración de afectos que no se plasman, que una consolidación real de una relación. El único que parece soportarlo es Quincho, al cual, sin embargo, Alfonso ignora cuando lo previene de la muerte de Teresa. Ello nuevamente enfoca el problema fundamental por el que se desplaza el personaje principal: la incomunicación con los demás y la imposibilidad de acceder a un futuro prometedor. El engaño a sí mismo es, nuevamente, la única opción que encuentra para protegerse de su inminente caída. Es esta otra de las grandes vertientes de la novela, pues la imposibilidad de comunicarse con los otros le cierra todos los portones y le define el rumbo de un camino en el que lo único que encuentra es la marca de una carencia, de la cual termina haciendo conciencia: su búsqueda de Teresa es, en principio, aliento y motivo; luego, deviene en desengaño y muerte. Es el fin de su búsqueda, el fracaso de un sueño y el cierre de sus ilusiones. Alfonso "muere" pleno de soledad y es ello lo que determina la idea pesimista que se desprende del texto.

El predominio de acontecimientos en tiempo pasado, ubicados de esta manera en tanto se hace alusión a lo vivido por Alfonso, especifican el predominio temporal que el texto posee. Ello se convierte en el pretexto que ha de desencadenar la narración y la historia de amor-desamor en que se ven envueltos ambos. Son diversos momentos en la vida de Alfonso, los cuales pesan demasiado aún en la madurez, por lo que inicia el retorno hacia el "hogar". La participación de tan pocos personajes en el texto contribuye a enfocar el relato en la persona de Alfonso y de Teresa, pese a la ausencia de esta. El fracaso del amor se enfoca desde la imposibilidad de un encuentro que no se lleva a la práctica. La búsqueda, por lo demás simbólica, del amor juventud, se convierte quizás en el intento desesperado de recobrar la inocencia a la cual ya no se tiene acceso. Alfonso regresa a "morir" después de culminar una peregrinación de varios años en la cual se prepara para redimirse sin lograrlo plenamente. Regresar a "la vida" se torna imposible, pues el implacable tiempo le impide retomar el pasado. Alfonso intenta re-crear lo ido, sin saber que no existe vuelta de hoja. Su vida como hoja de aire le 
impide regresar al lugar primigenio en igual situación. Su regreso es la vuelta a un lugar que es el mismo sin serlo igual, y que es igual sin ser el mismo. Es la inevitabilidad de nuevos espacios que nunca fueron realmente los suyos y que en el momento en que regresan aún menos lo han de ser.

La concentración del tiempo presente, ubicado en el momento del relato que le efectúa el mismo Alfonso a Quincho, propicia el desencadenamiento de la historia. Ello constituye, por lo tanto, el elemento que justifica el regreso, por lo que se insiste en la idea de que $L a$ hoja de aire es la historia de un encuentro que se desencuentra, pues no se logra el acceso a la persona ideal y deseada, motivadora del relato. La partida de Alfonso hacia ella, al final del texto, no culmina necesariamente con el objetivo deseado por este, pues el sueño desencadenado camina hacia el amargo despertar de este, siempre y cuando no siga con la locura que sustituye y permite el escape citado. La locura en la que se refugia y que le permite cuestionar, pero que también le desplaza en la sociedad, se vuelve insuficiente como elemento vital de su existencia. La aplicación conciente o inconciente de esta (y que está claro que no se trata de la locura estereotipada que lleva al encerramiento y a la privación de la libertad espacial de los sujetos, por medio de la reclusión en ámbitos determinados para tal fin, sino de un estado de desligamiento social provocado por una actitud de separación ante la imposibilidad de compartir funciones sociales para las cuales existe una negatividad por parte del sujeto) hace que Alfonso siga una línea actancial que lo lleva a la sima. La hoja de aire sometida al vaivén del aire (la sociedad) y desprendida del árbol (de nuevo las estructuras sociales establecidas) para caer en el olvido, de donde no se regresa.

Por otra parte, la experiencia del circo es la paradoja del reír y hacer reír (era payaso) aun cuando el sufrimiento y la soledad eran lo predominante. Su fracaso como tal, en esta y cualquier otra ocupación, advienen como excusa para el regreso. Sin embargo, el encuentro con el antiguo "amigo" redefine, simbólicamente, lo que ha de ser su llegada a la patria. La escucha del narratario (Quincho) no es sino una excepción en medio del caos al cual arriba y al que no logra acoplarse. De hecho, Quincho es incapaz de redireccionar el pensamiento de Alfonso. Quincho escucha la narración de este, por lo cual se convierte en mero recipiente, imposibilitado de "crear conciencia" en el recién llegado. Sus palabras no tienen asidero en los propósitos del amigo y se vuelve mero testigo de lo que representa la llegada del repatriado. Es la antítesis de Pedo de Culebra, al cual ya hemos señalado como el referente de una sociedad en crisis.

La felicidad de la cual se ve posesionado Alfonso al final del texto se constituye en la máscara de lo que ha de ser el verdadero cierre: la tranquilidad no está en el regreso, sino que este es una "apariencia" de la que ha de sustraerse por sí mismo o por los demás, pues regresa preso de recuerdos que ya no corresponden a lo que encuentra. Su vida, sujeta a los azares que le va tendiendo el destino, con fracasos y éxitos (estos últimos más pasajeros que perdurables) lo obligan a refugiarse en la negación del entorno al descubrir a Teresa en otras mujeres y negarse a aceptar la noticia de su amigo, el cual le revela la muerte de esta. La renuncia cerraría el texto, mientras la negación da margen a la búsqueda en la cual decide enfrascarse: el ideal de una mujer que ya ni siquiera existe, la Dulcinea imposible de alcanzar.

Así, La hoja de aire es la historia de una desposesión paulatina de vida, que da margen a un desplazamiento simbólico de la caída que experimenta el personaje, incapaz de rescatar las cenizas del pasado. La confirmación de la caída no le permite acceder a la nostalgia de lo ido. La búsqueda de Teresa es el intento de llegar a lo imposible. Esta no existe, se ha 
quedado en el pasado, lo que refuerza la idea misma del texto, el cual reafirma que la hoja no se detiene con su regreso, pues su llegada se constituye en el inicio de un fracaso mayor: está desligado de una familia disgregada, obsesionado con un reencuentro que no es más que el encuentro con un pasado que adquiere la noción de un presente marcado por el desencuentro con todo: el fracaso con los amigos de antaño, la muerte de los padres, la separación de su hermana, la muerte de su ex novia, la inadaptación a un medio que le resulta hostil, que él mismo rechaza y con el que entra en conflicto permanente. El entorno es una relación imposible, un acercamiento que no logra culminar, ni busca hacerlo. El regreso a la búsqueda es, paradójicamente, el proceso de alejamiento por el que transita Alfonso. La desesperanza que teje el texto es la mayor excusa de la consolidación de la metáfora existencial que gobierna la vida de este: la hoja que no cesa de ir de un lugar a otro, pero carente de sueños. El engaño que se brinda a sí mismo al final del relato no hace más que abrir el sentido del engaño, que se refuerza con la apertura del texto: se abre la dimensión a la mentira y se perpetúa con ello el engaño, al cual se halla sujeto el personaje principal. La locura es la excusa para seguir siendo la hoja de aire; es la posibilidad de la diferencia que lo separa de los demás. La incomprensión deviene en rasgo característico de su propia individualidad. De allí su desapego de las normas sociales:

\footnotetext{
Yo no sé qué me pasó, pero lo cierto es que en un trun el corazón se me puso bucólico, me dio un arranque de esos que me dan a veces, me quité la bata y quedé así, tal como Dios me echó al mundo, delante de aquellos ojos olorosos a yerbabuena y a melcochas en hojitas de naranja. ¡Qué alarido pegó! (Gutiérrez 1985: 46).
}

Esta cita confirma el hecho de que Alfonso actúa de acuerdo con criterios que van más allá de lo establecido dentro de los valores preestablecidos y, por lo tanto, ello linda con la locura, con el descentramiento de la norma (asociado con lo normal) y le es cobrado por todos, pese a que su talento lo revela, en gran medida, superior a los demás.

Además, no deja de llamar la atención el hecho de que su desnudez, la mostración de esta ante la empleada, poseedora de "...ojos olorosos a yerbabuena y a melcochas en hojitas de naranja" remite a cierta idea nostálgica de lo pasado, lo cual nos lleva a pensar en la imagen que comporta un intento de regreso al pasado, como forma desesperada y simbólica. Mostrarse como Dios lo "echó" al mundo es la reminiscencia de lo primigenio de cada ser humano, el retorno al encuentro con la vida, y es ello lo que intenta realizar Alfonso: reencontrarse con la vida, la cual se ha quedado estacionada en el pasado y que ha regresado a buscar en la figura de Teresa. El desencuentro con la vida no es, por lo tanto, sino el encuentro con la muerte, y por eso al final de la novela no logra evadir esta. La empleada, como vestigio del pasado del cual se ha desligado durante veinte años, lo rechaza como símbolo de que el pasado ya le es imposible, ya se niega a aceptarlo, pues ha cambiado, tal como él lo ha hecho. Es un encuentro imposible entre dos entes que ya no son los mismos, por lo cual la re-identificación se hace inalcanzable. Ello aumenta su "locura" y lo termina de separar de los demás, quienes lo ven incluso como peligroso, tal como ocurre con la empleada, con su hermana y su cuñado. Ese carácter peligroso, asociado a la locura, es la mejor forma de reducirlo y anularlo socialmente, a lo que contribuye al insistir en el encuentro con su antiguo amor. La diferencia, dada por la locura, cierra el texto y lo abre, en una relación casi cíclica del sentido textual. He allí el gran mérito de la historia escrita por Joaquín Gutiérrez. 
Por otra parte, el hacer textual se permite fundar y fundir "su verdad" a partir de una literariedad que hace del texto un producto y un productor de sentido. Este relato produce, por lo tanto, la locura de un personaje que es también productor de sí mismo en su relación con los demás. La negación a la locura de la cual es manifiesta su expresión en Alfonso en los diversos momentos en que se va gestando la historia, se vierte en un pre-texto para alimentar la textualidad misma. La locura de Alfonso es la excusa que este encuentra para dar cabida al desarrollo y darse cabida a sí mismo. El encuentro como desencuentro al que se ve permanentemente sujeto, lo empuja a actuar ante los demás y a lindar locura y actuación como elementos vitales a los que se aferra para seguir viviendo. Así, la locura es la permisividad misma que construye el personaje (y no que lo construye) con el fin claro de llevar y conllevar su existir. La locura es el medio para no volverse loco, paradójicamente, sino para intentar seguir cuerdo. La locura es una especie de placer con el cual se recubre el personaje para alimentar el discurso... su discurso.

La palabra cumple, entonces, la función de engaño para desatar la búsqueda del sentido. Alfonso encuentra este sentido a partir de la mentira, búsqueda por lo demás muy cómoda y también muy efectiva en el devenir de cada hombre; de ahí que sea el arma más eficaz que encuentra para allanarse su camino. Sin embargo, la búsqueda de una Teresa que casi se vuelve fantasmal le otorga al relato un aura de texto casi fantástico en el que el intento de hallazgo está signado por la derrota y el fracaso. El personaje se refugia en un afán de reencuentro que no cesa, pero que tiene como término la imposibilidad. Alfonso está marcado como el personaje que, en un constante ir y venir, se halla siempre a la espera de un encuentro que no culmina; es la hoja de aire que no termina de ser llevada por el destino en una temporalidad incesante para este. El mismo viaje a Cartago es la marca clara de ese ir que se inicia permanentemente; es la presencia del ciclo que lo lleva a la locura ya señalada.

Así, el texto es, por lo tanto, el viaje a la locura (¿cordura?) y a la muerte que, según ha sido señalado, puede ser física, simbólica o incluso ambas. Volver a la patria no es un acto de reconocimiento y de renacimiento, sino de muerte y de enfrentamiento con el pasado, para terminar descubriendo que algunas cosas cambian, pero no otras, pues los seres humanos están sujetos, como hojas de aire, al devenir de los acontecimientos, aunque de alguna manera Alfonso haya construido sus veinte años de ausencia para terminar destruyendo los nexos con el pasado, aún contra su voluntad. Teresa ya es inasible, como sus sueños, y ello confirma que su suerte está echada, pues ha contribuido a la transformación de su propia existencia, la cual ha tomado ese rumbo.

Finalmente, el desarrollo de la historia es la contextualización de la locura de Alfonso que se teje alrededor de este como uno de los ejes desencadenantes de la diégesis. El tejido textual es, por lo tanto, la trama de una renuncia que no se efectúa sino que se deja de lado, se desecha para dar paso a la excusa que desata la productiva locura textual y personal que se presentan en la novela. Alfonso es el "loco cuerdo" que se conduce a lo largo de la obra como un (des)atado cuestionador. Lo demás es apenas la manifestación propia de una locura que se torna contestataria, como muchas de las locuras que se oponen a plegarse a la imposición de un entorno avasallador. Esto explica el discurso de Alfonso: es el juego del discurso puesto en funcionamiento con el disfraz de la palabra. Alfonso juega, se divierte y se extravía en su propio mundo. Lo demás es el rumbo que le teje el discurso y la liberación y apertura del significante-significado; es la puesta en escena de su propia actuación, de su práctica como actor, en una trama en la cual es la tragedia existencial y la imposibilidad de vencer las convenciones 
sociales lo que termina llevándolo a su fin. La tragedia de la vida que lo precede y lo sobrepasa lo coloca como una marioneta en todo un entramado que él contribuye a construir, paradójicamente, pues ha intentado separarse de él sin darse cuenta de que, cuanto más lo intentaba, más ayudaba a fortalecer los hilos que lo movían ante los demás. Es una hoja de aire que se desliza suavemente, pero en una caída irreversible.

Su búsqueda para que los demás lo entiendan, tal como él lo dice, aunque sea un poquito, se torna ambigua con el cierre del relato: la búsqueda del cordel con el cual ha de colgar la hoja que Teresa le regaló. Alfonso es hoja que ha de ser colgada. La apertura del texto termina abriendo, por lo tanto, la ambigüedad y desencadenando una nueva búsqueda: la del lector curioso arrebatado a la historia contagiado de la búsqueda infinita de sucesivas búsquedas. Es el cierre que se abre con una ambigüedad que contribuye a una nueva apertura del texto... la dimensión de una nueva obra, a la cual el lector asiste y ante la cual necesita establecer una interpretación. La novela no termina donde se cierra, sino donde termina la interpretación del lector, que a partir de ese momento, deviene autor, para poner en el aire, de nuevo, a la hoja que se niega a caer.

\section{Bibliografía}

Arias Formoso, Rodolfo. 2002. Retrato de Joaquín Gutiérrez. San José: Editorial de la Universidad de Costa Rica.

Gutiérrez, Joaquín. 1985. La hoja de aire. Cuarta edición. San José: Editorial Costa Rica. 1989. Obras completas (volumen II). San José: Editorial de la Universidad de Costa Rica.

Oviedo, Lucrecia. 1993. Joaquín Gutiérrez: novelista. San José: Editorial Costa Rica.

Romero, Mario. 1979. Análisis estructural de La hoja de aire. Tesis de Grado: Universidad de Costa Rica. 